\title{
Alzheimer's Disease: The Features and Quality of Life
}

\author{
Mustafa M. Amin \\ Faculty of Medicine, University of Sumatera Utara, Jalan dr. Mansur No 5 Medan 20155, Sumatera Utara \\ E-mail of the corresponding author: noki4gozo@yahoo.com
}

\section{Introduction}

Among neurodegenerative disease, dementia is the one which affected cerebral cortex. (Grabowski and Damasio, 2004). It has enormous price to community, i.e., higher cost to health and social services, directly and economic price regarding lost productivity of the carers, and families who give funding for the patients, indirectly. One of its type is Alzheimer's disease (AD). First described by Alois Alzheimer in the early 20th century, he mentioned a middle-aged woman who had cognitive impairment, lower functional level, and experienced psychotic symptoms, i.e., auditory hallucinations, and delusions. (Lovestone, 2009). He also found neurofibrillary tangles and milar foci in his case. (Richards and Sweet, 2009).

Old-age people experience mild declining of memory, executive functioning, and agility to cognitive processing related to their aging process within normal limitation, however it is a different condition with the patients with dementia, they experience all of the symptoms, progressively. (Solfrizzi et al., 2002). Nowadays, there is increasing prevalence of dementia. It is doubled from 5 to 8 percent at age 65 to 70 , to 15 to 25 percent at age 75 to 80 , and up to 40 to 50 percent over age 85. In 2050, there will be 11 to 16 million people with AD in United States of America, because of the increasing of aging population. (Richards and Sweet, 2009), and in United Kingdom there will be almost 1.8 million people with dementia by 2051.(Knapp et al., 2007). The clinical features of $\mathrm{AD}$ are: cognitive impairment, functional impairment, and neuropsychiatric manifestations, i.e., disturbing behaviour, changing mood, anxiety, changing personality, sleep disturbances, and psychosis. (Richards and Sweet, 2009; Lovestone, 2009).

\section{Definition}

Dementia is multiple cognitive deficits which develop in old age (usually above 65 years), manifested by impairment in the memory and at least impairment in one of the following area of cognitive, i.e., language, gnosis,praxis, and executive functioning, however, the consciousness is clear. (American Psychiatric Association, 2000; Richards and Sweet, 2009).

Among dementia the most frequent type is $\mathrm{AD}$, it is defined by amyloid beta plaques, neurofibrillary tangles, and widespread loss of neurons, histologically. (Bennett, 2007; Lovestone, 2009; Fuller and Manford, 2010; Augustine, 2012; Anonymous, 2013).

\section{Cognitive and Behavioural Features of Alzheimer's Disease}

The gold standard for dementing illness when comparing it between each other is AD. The features of AD are well-characterized. (Levy and Chelune, 2007). The list below summarize the cognitive and behavioural features of $\mathrm{AD}$ :

\section{Cognitive Impairment}

Patients with dementia suffer from memory impairment, language impairment (aphasia), inability to do motor activities, although motor function is intact (apraxia), inability to recognize object, although the sensory function is intact (agnosia), and impairment in judgment, executive functioning, and visuospatial functioning. (Levy and Chelune, 2007; Lovestone, 2009; Richards and Sweet, 2009).

2. Functional Impairment

There must be a significant functional impairment compared with the previous level of functioning. (American Psychiatric Association, 2000). The deterioration of daily functioning of the AD patients have the most impact for them, and they need care for themself, as well as nursing- home residency, because of it. (Knapp et al., 2007; Lovestone, 2009; Alzheimer's Association, 2012). There is also impairment in social functioning of dementia patients, resulting in withdrawal in social activities. (Richards and Sweet, 2009).

3. Neuropsychiatric Symptoms

The most frequent of mood disturbance in $\mathrm{AD}$ patients is depression (Lovestone, 2009), occurring about half of patients with AD (Richards and Sweet, 2009), whilst mood elation, hypomania, and disinhibition are rare. (Lovestone, 2009; Richards and Sweet, 2009). The most common psychotic symptoms are: paranoid ideation, hallucination, and delusion. The personality is changed to somewhat their relatives describe as a 'living bereavement', and the patients might become fearful, anxious, flattening of affect, and experience apathy syndrome. (Lovestone, 2009; Richards and Sweet, 2009).

4. Other Behavioural Symptoms 
Patients with $\mathrm{AD}$ also experience altered circadian rhythm, incontinence, eating pattern, wandering, and aggression. (Lovestone, 2009; Richards and Sweet, 2009).

\section{The Relationship between Neuropathology and Cognitive and Behavioural Features of Alzheimer's} Disease

\subsection{Neurotransmitters}

\subsubsection{Acetylcholine}

Francis et al (1999), Sarter and Parikh (2005) have reviewed, at first, the studies of atropine and scopolamine which showed they impaired cognitive abilities in animals and humans, thus cholinergic system had an important role in cognitive functions. In another review by Tampi et al (2011), the cholinergic systems have experienced pathological state which cause Behavioural and Psychological Symptoms of Dementia (BPSD) over denervation of temporal and frontal cortices, and as Minger et al (2000), cited by Garcia-Alloza et al (2005) have written, BPSD may be linked with the absence of choline. Garcia-Alloza et al (2005) have also found, aggressive behaviour have been related to low levels of cholineacetyltransferase (ChAT) and acetylcholinesterase (AChE). Almost a decade ago, there was a consensus that cholinergic augmentation was effective in developing memory, concentration, attention, and psychiatric symptoms of $\mathrm{AD}$, discreetly. (Grabowski and Damasio, 2004). Until now, many drug studies have been done in relation with the cholinergic neurons in $\mathrm{AD}$.

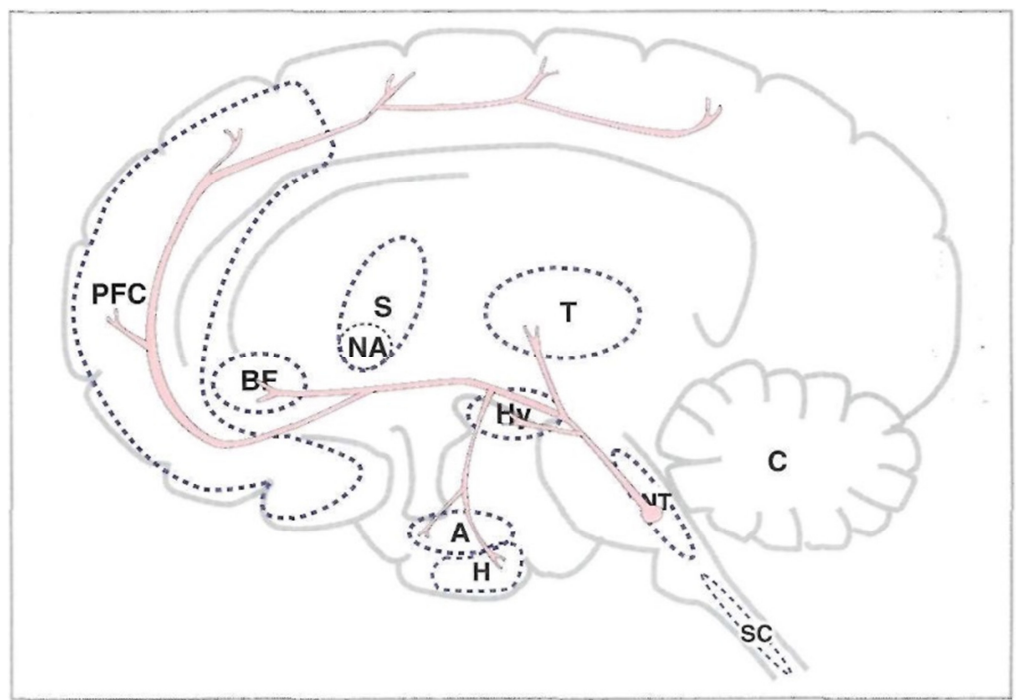

Figure 1. Major acetylcholine projections via brainstem. Major neurotransmitter projections, part 4: acetylcholine via brainstem. Acetylcholine projections originating in the brainstem extend to many brain regions, including the prefrontal cortex, basal forebrain, thalamus, hypothalamus, amygdala, and hippocampus. These projections may regulate arousal, cognition, and other functions. PFC, prefrontal cortex; BF, basal forebrain; S, striatum; NA, nucleus accumbens; T, thalamus; HY, hypothalamus; A, amygdala; H, hippocampus; NT, brainstem neurotransmitter centers; SC, spinal cord; C, cerebellum. Adapted from: Stahl, S.M. (2008). Stahl's Essential Psychopharmacology Neuroscientific Basis and Clinical Applications. 3rd ed. New York: Cambridge University Press. 


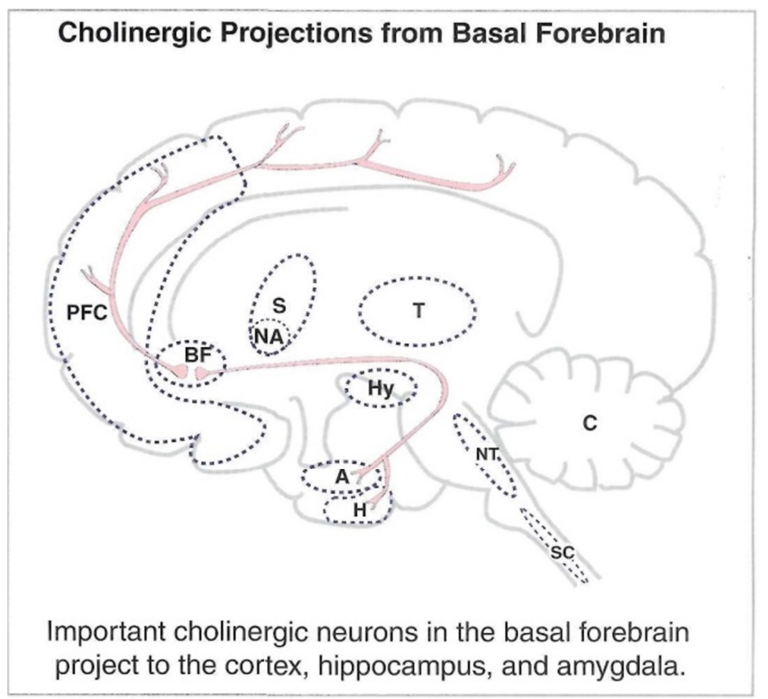

Figure 2. Major acetylcholine projections via basal forebrain. Major neurotransmitter projections, part 5: acetylcholine via basal forebrain. Cholinergic neurons originating in the basal forebrain project to the prefrontal cortex, hippocampus, and amygdala; they are believed to be involved in memory. PFC, prefrontal cortex; BF, basal forebrain; S, striatum; NA, nucleus accumbens; T, thalamus; HY, hypothalamus; A, amygdala; H, hippocampus; NT, brainstem neurotransmitter centers; SC, spinal cord; C, cerebellum. Adapted from: Stahl, S.M. (2008). Stahl's Essential Psychopharmacology Neuroscientific Basis and Clinical Applications. 3rd ed. New York: Cambridge University Press.

4.1.2 Serotonin

Tampi et al (2011) have reviewed, auditory and visual hallucinations were associated with serotonin receptor polymorphism, and the presence of visual hallucination was associated with Ser23 allele. It was concluded that psychosis and behaviour phenotype were associated with the serotonin transporter promoter region (5-HTTPR) I allele. In another study by Garcia-Alloza (2005), they found that overactivity was associated with 5hydroxytryptamine (5-HT) levels in Brodmann area 10 (frontal cortex), and psychosis was associated with 5-HT levels in Brodmann area 20 (temporal cortex). They also found women with AD experienced delusions higher than men, in relation with the ratio of 5-HT/ AChE in temporal cortex.

4.1.3 Dopamine

It has been thought that symptoms of aggression and psychosis in white subjects with AD have been related with dopamine receptor genes DRD1 B2/ B2 homozygotes, and the carriers have been more likely to experience hallucination and be aggressive. Psychosis has been related with the DRD3 1/ 1 or 2/ 2 homozygotes, and DRD3 polymorphism. Delusions have been experienced by the carriers of DRD3 1 allele. (Sweet et al., 1998; Holmes et al., 2001).

\subsection{Amyloid $\beta$ Protein (A $\beta$ Protein)}

Recently, it is known that the cognitive disturbance in patients with AD is because of widespread synapses loss in cortical regions. The cause of synaptotoxicity in $\mathrm{AD}$ is the self-aggregation of $\mathrm{A} \beta$ into soluble low-n oligomers. Animal and postmortem studies have complemented in vitro studies that has shown on synapses the deleterious effect of $A \beta$ oligomers. In human studies, soluble $A \beta$ associated with synapse loss and cognitive impairment, in the early event of AD. (Richards and Sweet, 2009). Another evidence shows that mutations in amyloid precursor protein (APP), resulting from unindirectional cascade, has risen to neurofibrillary tangle and plaque formation, whilst in tauopathies, although mutation in tau gene has risen tangle formation, there is not plaque formation. (Lovestone, 2009).

\subsection{Apolipoprotein $\varepsilon(A P O E)$}

Apolipoprotein $\varepsilon 4$ allele gene (APOE4) is related with the late-onset AD. The risk of people who carry APOE4 in familial or sporadic cases are higher than people who do not carry it. Two- to fourfold increased risk have been found for people who have a copy of APOE4, and four- to eightfold increased risk for people who have two copies of it. (Richards and Sweet, 2009). Tampi et al (2011) have reviewed that in patients with AD: 1) The 3/ 4 genotype of APOE4 caused higher rates of psychosis and depression when compared to control, 2) Significantly lower epsilon 2 allele of APOE in the depressive group when compared to control and it caused symptoms of depression in late-onset $\mathrm{AD}$. 


\section{The Interplay of Cognitive and Behavioural Features of Alzheimer's Disease, Environmental and Social Factors, and Their Relative Influences to Patients Quality of Life}

Kasl-Godley and Gatz (2000) have reviewed, the demented people have well defined cognitive and functional impairments, however, their subjective experience of these impairments are the area which need further investigations. It might be undetected, underutilized, and coping and adaptation are unfacilitated because of the limited information. For example, symptom of depression, which is frequent among patients with $\mathrm{AD}$, it reflects sadness because of inability to function dependently, and loss of intellectual capabilities, together with attenuation of control and mastery. The cognitive and behaviour symptoms of patients with dementia are not only an expression of the elemental disease mechanism, however they also show the environmental and social context, as well as patient's reactions and perception. Spector et al (2000), have reviewed it is important for the patient with $\mathrm{AD}$ to get better understanding of his/ her environment, which will improve his/ her self-esteem and sense of control. An appropriate design of the structure and lightning of their environment can improve activities of daily living, e.g., taking shower, wearing clothes, and consuming food.

Alzheimer's Disease could have effects for the patients, e.g., inability to get around home and functioning which lead to confusion, losing independence, and reduce self-esteem because of physical and mental changes which lead to social isolation, difficulties in planning activities and completing tasks which lead to relatives help and increased anxiety about future. (WebMD, 2013). Therefore, it is an important thing to educate the patients, the patients's family and their caregivers. For the patients, education is needed to give information about, e.g., improving their compliance to medications, the benefit of doing exercise, healthy diet, and cognitive stimulation. For the family members, education is to give advices about, e.g., safety concerns associated with falls, driving, fire arms, living alone, and social engagement. As for the caregivers, they should be educated about, e.g., sleep hygiene and daily schedule, strategies to prevent stress and lassitude, future need for long-term care placement, and dealing and treating with behavioural and psychological issues. (Manepalli $e t$ al., 2009).

Samus et al (2005) have reviewed, quality of life has a subjective component in its traditional definition, which is, the individual has the chance to rate her or his own quality of life. In patients with dementia, some of them are incompetent in reflecting their internal states. Thus, it is important to find and develop which quality of life rating scale that suits for every patient. Gonzalez-Salvador et al (2000) have studied, worse orientation, depressive symptoms, increased functional dependence, and anxiolytics treatment were associated with low quality of life. In one study, Samus et al (2005) have concluded, the care environment did not have an impact in quality of life, however, symptoms of aggression and agitation were correlated with it. In the future, studies in relation with quality of life of patients with AD should have been done to gain further knowledge about it.

\section{Conclusion}

People will have a greater risk to develop AD as they grow older, and it is a debilitating disease for them, as it continues to progress to the further stage. Their condition is getting worse when it has reached the last stage of the disease. The clinical features of AD are: cognitive impairment, functional impairment, and neuropsychiatric symptoms. All of these features have been thought to be related with the neurotransmitters, A $\beta$ Protein, and APOE. They are disturbing for the patients, their family, and the caregivers which can change their lifestyle. A full understanding of the disease could reduce the stress between the patients, their family, and the caregivers.

The cognitive and behavioural features of AD are related with the patient's quality of life. Therefore, these features have to be managed and treated properly. The lifestyle management and psychosocial intervention can improve quality of life of patients with AD. It requires strong effort and motivation from patients, their family members, and caregivers to gain an exceptional quality of life for the patients with AD. Designing the appropriate treatment for each patient with $\mathrm{AD}$ is important to develop their quality of life. Hence, more studies are needed to conclude which treatment and management might increase the quality of life of patients with AD.

\section{References}

Alzheimer's Association. 2012 Alzheimer's Disease Facts and Figures. [Online]. Available at: http://www.alz.org/downloads/facts_figures_2012.pdf [Accessed 28 January 2013].

American Psychiatric Association. (2000). Diagnostic and Statistical Manual of Mental Disorders. 4th ed. Text revision. Washington, DC: American Psychiatric Association.

Anonymous. Merriam-Webster Encyclopedia. [Online]. Available at: http://www.merriamwebster.com/medical/alzheimer's\%20disease [Accessed 15 January 2013].

Augustine, G.J., Fitzpatrick, D., Hall, W. C., et al. (2012). Memory. In Purves, D., Augustine, G,J., Fitzpatrick, D., et al. (eds). Neuroscience. Chapter 31. 5th ed. Sunderland: Sinauer Associates, Inc.

Bennett, M.V.L., Berridge K.C., Berson, D., et al. (2007). Neurons and Glia. In Bear, M.F., Connors, B.W., Paradiso, M.A. (eds). Neuroscience Exploring the Brain. Chapter 2. 3rd ed. Philadelphia: Lippincott Williams \& 
Wilkins.

Francis P.T., Palmer, A.M., Snape, M., and Wilcock, G.K. 'The cholinergic hypothesis of Alzheimer's disease: a review of progress.' J Neurol Neurosurg Psychiatry, 66, 137-47.

Fuller, G., and Manford, M. (2010). Neurology An Illustrated Colour Text. 3rd ed. Edinburgh: Elsevier Limited. Garcia-Alloza, M., Gil-Bea, F.J., Diez-Ariza, M., et al. (2005). 'Cholinergic-serotonergic imbalance contributes to cognitive and behavioural symptoms in Alzheimer's disease.' Neuropsychologia, 43, 442-49.

Gonzalez-Salvador, T., Lyketsos, C.G., Baker, A., et al. (2000). 'Quality of Life in Dementia Patients in LongTerm Care.' Int J Geriat Psychiatry, 15, 181-9

Grabowski, T.J., and Damasio, A.R. (2004). Definition, clinical features and neuroanatomical basis of dementia. In Esiri, M.M., Lee, V.M.Y., and Trojanowski, J.Q. (eds). The Neuropathology of Dementia. Chapter 1. 2nd ed. New York: Cambridge University Press.

Holmes, C., Smith, H., Ganderton, R., et al. (2001). 'Psychosis and aggression in Alzheimer's disease: the effect of dopamine receptor gene variation'. J Neurol Neurosurg Psychiatry, 71, 777-9.

Kasl-Godley, J., and Gatz, M. (2000). 'Psychosocial Interventions for Individuals with Dementia: An Integration of Theory, Therapy, and A Clinical Understanding of Dementia.' Clin Psych Review, 20, 6, 755-82.

Knapp, M., Prince, M., Albanese, E., et al. (2007). Dementia UK The Full Report. London: Alzheimer's Society. Levy, J.A., and Chelune, G.J. (2007). 'Cognitive-Behavioral Profiles of Neurodegenerative Dementias: Beyond Alzheimer's Disease'. J Geriatr Psychiatry Neurol, 20, 227-38.

Lovestone, S. (2009). Dementia: Alzheimer's disease. In Gelder, M.G., Andreasen, N.C., López-Ibor Jr, J.J., and Geddes, J.R. (eds). New Oxford Textbook of Psychiatry. Section 4. Vol 1. 2nd ed. New York: Oxford University Press, 333-41.

Manepalli, J., Desai, A., and Sharma, P. (2009). 'Psychosocial-Environmental Treatments for Alzheimer's Disease.' Primary Psychiatry, 16, 6, 39-47.

Richards, S.S., and Sweet, R.A. (2009). Dementia. In Sadock, B.J., Sadock, V.A., and Ruiz, P. (eds). Kaplan \& Sadock's Comprehensive Textbook of Psychiatry. Chapter 10. Vol 1. 9th ed. Philadelphia: Lippincott Williams \& Wilkins, 1167-97.

Samus, Q.M., Rosenblatt, A., Steele, C., et al. (2005). The Association of Neuropsychiatric Symptoms and Environment With Quality of Life in Assisted Living Residents With Dementia.' The Gerontologist, 45, 1, 1926.

Sarter, M., and Parikh, V. (2005). 'Choline Transporters, Cholinergic Transmission, and Cognition.' Nature Neuroscience, 6, 48-56.

Solfrizzi, V., Panza, F., Torres, F., et al. (2002). 'Selective Attention Skills in Differentiating between Alzheimer's Disease and Normal Aging.' J Geriatr Psychiatry Neurol, 15, 99-109.

Spector, A., Davies, S., Woods, B., and Orrell M. (2000). 'Reality-Orientation for Dementia: A Systematic Review of the Evidence of Effectiveness from Randomized-Controlled Trials.' Gerontologist, 40, 2, $206-12$.

Stahl, S.M. (2008). Stahl's Essential Psychopharmacology Neuroscientific Basis and Clinical Applications. 3rd ed. New York: Cambridge University Press.

Sweet, R.A., Nimgaonkar, V.L., Kamboh, M.I., et al. (1998). 'DOpamine Receptor Genetic Variation, Psychosis, and Aggression in Alzheimer's Disease.' Archive Neurol, 55, 1335-40.

Tampi, R.R., Williamson, D., Muralee, S., et al. (2011). 'Behavioral and Psychological Symptoms of Dementia: Part I - Epidemiology, Neurobiology, Heritability, and Evaluation.’ Clinical Geriatrics, 1-6.

WebMD. Coping with Daily Life and Alzheimer's Disease. [Online]. Available at: http://www.webmd.com/alzheimers/guide/coping-daily-life [Accessed 28 January 2013]. 
The IISTE is a pioneer in the Open-Access hosting service and academic event management. The aim of the firm is Accelerating Global Knowledge Sharing.

More information about the firm can be found on the homepage:

http://www.iiste.org

\section{CALL FOR JOURNAL PAPERS}

There are more than 30 peer-reviewed academic journals hosted under the hosting platform.

Prospective authors of journals can find the submission instruction on the following page: http://www.iiste.org/journals/ All the journals articles are available online to the readers all over the world without financial, legal, or technical barriers other than those inseparable from gaining access to the internet itself. Paper version of the journals is also available upon request of readers and authors.

\section{MORE RESOURCES}

Book publication information: http://www.iiste.org/book/

Academic conference: http://www.iiste.org/conference/upcoming-conferences-call-for-paper/

\section{IISTE Knowledge Sharing Partners}

EBSCO, Index Copernicus, Ulrich's Periodicals Directory, JournalTOCS, PKP Open Archives Harvester, Bielefeld Academic Search Engine, Elektronische Zeitschriftenbibliothek EZB, Open J-Gate, OCLC WorldCat, Universe Digtial Library, NewJour, Google Scholar

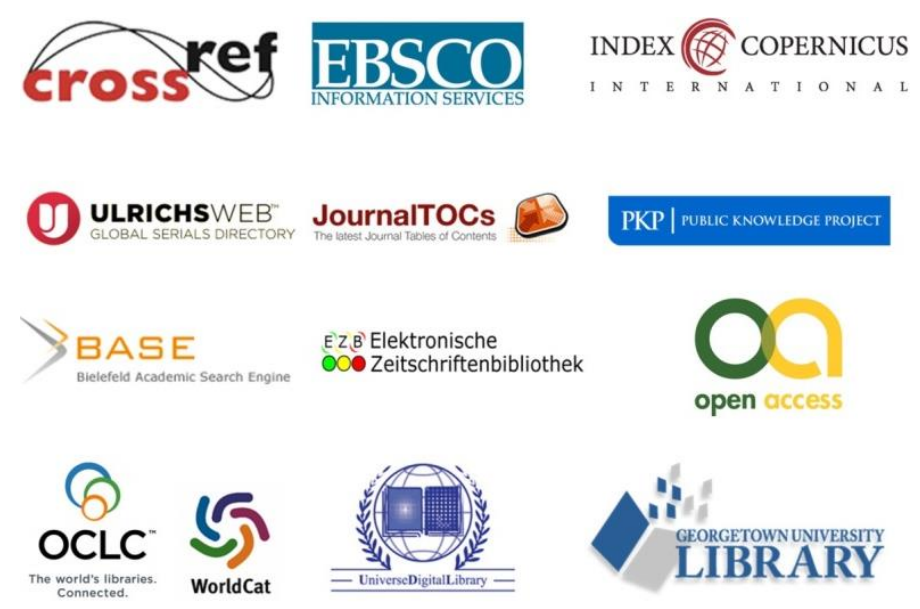

